\title{
ARTIGOS
}

\section{DA UNIDADE/DIFERENÇA À MODALIDADE: A ARQUEOLOGIA DA ONTOLOGIA NO PENSAMENTO DE GIORGIO AGAMBEN*}

\author{
Ana Suelen Tossige Gomes** \\ anatossige@gmail.com
}

Andityas Soares de Moura Costa Matos*** vergiliopublius@hotmail.com

RESUMO Um retorno ao ser aparece na contemporaneidade como uma via teórica importante para se pensar as possibilidades de uma política e de uma ética livres das conformações legadas pela história do Ocidente. É nesse sentido que Giorgio Agamben desenvolve em "O uso dos corpos" o que chamará de uma arqueologia da ontologia, buscando verificar se o acesso a uma ontologia ainda é possivel nos dias de hoje. Partindo de Aristóteles, passando pela escolástica, até chegar a Heidegger, Agamben evidencia como a divisão binária do ser - em duas experiências contrapostas e ao mesmo tempo dependentes - mantém-se como uma aporia no pensamento e na práxis ocidental. A ontologia, como lugar originário da articulação histórica entre linguagem e mundo, é então percorrida por suas fraturas, levando o filósofo a propor uma nova leitura do ser a partir do que entende como ontologia modal. A partir dessas ideias, busca-se investigar como essa articulação medial entre essência e existência, ser e ente, comum e singular - constituída sempre em devir - propiciaria uma nova perspectiva do ser, na qual ontologia e ética se confundem.

* Artigo submetido em 30/07/2017. Aceito em 05/10/2017.

** Universidade Federal de Minas Gerais - UFMG, Belo Horizonte, MG, Brasil.

*** Universidade Federal de Minas Gerais - UFMG. Belo Horizonte, MG, Brasil.. 
Palavras-chave Giorgio Agamben, Arqueologia da ontologia, Ontologia modal.

ABSTRACT $A$ return to the being emerges in the contemporaneity as an important theoretical way to think about the possibilities of a politics and an ethics free from the legacy bequeathed by the Western history. In this sense, Giorgio Agamben develops, in the book "The use of the bodies", what he calls an archaeology of ontology, seeking to verify if the access to an ontology is still possible nowadays. Starting from Aristotle, passing by the Scholastics, until arriving at Heidegger, Agamben highlights how the binary division of beingin two opposed and, at same time, dependent experiences - remains an aporia in Western thought and praxis. The ontology, as the origin of the historical articulation between language and world, is then traversed by its fractures, leading the philosopher to propose a new reading of the being from what he understands as modal ontology. From these ideas, we intend to investigate how this medial articulation between essence and existence, being and entity, common and singular-always founded in a becoming - would provide a new perspective of the being in which ontology and ethics end up mixed.

Keywords: Giorgio Agamben, Archaeology of ontology, Modal ontology.

\section{Introdução}

O acesso a uma filosofia primeira era para os gregos o problema filosófico por excelência. Desde os filósofos jônicos até Aristóteles, a busca pela origem arkhé - manteve-se como centro de investigação da natureza e do funcionamento de todas as coisas, perpassando todo o período clássico. As posições dos filósofos que vão do século VI ao século III a. C., contudo, são bastante diferentes: vê-se desde a busca por uma natureza (phýsis) comum, constituinte do ser, até um entendimento metafísico sobre o ser.

Foi Aristóteles que no século III a. C. ligou a ontologia ao momento antropogenético, relacionando ser e linguagem, e inaugurando uma das diferenciações que marcará fortemente toda a história ética e política do Ocidente: a distinção entre o humano e o animal. ${ }^{1}$ Ao afirmar o caráter político da espécie humana, Aristóteles introduz o discurso como o dado distintivo da possibilidade da existência política capaz de uma experiência ética autêntica, que para o grego

1 Trata-se da passagem 1253a, de "Política". 
coincidiria com a vida na pólis. A articulação entre linguagem e mundo atribui sem dúvida um traço de historicidade ao ser, mas ele apenas se sustenta a partir do elemento metafísico: o entendimento de que certa realidade é a finalidade decorrente da natureza mesma das coisas. Isto é, o dado antropogenético, embora histórico, faz parte da própria natureza do ser, que se manifesta, para Aristóteles, segundo uma teleologia.

No pensamento moderno, entretanto, a ontologia perde esse sentido. Com a negação da metafísica em sua filosofia da consciência, Kant torna a ontologia algo impossível. Todavia, a manutenção da metafísica em sua razão prática fez do transcendental o elemento separador do pensamento daquele a priori histórico - o evento antopogenético (articulação entre linguagem e mundo) - que para o pensamento ocidental governava a origem e a manifestação do ser. Nesse pensamento, que será continuado por uma série de "filósofos profissionais" neokantianos, "a ontologia se transforma [...] em gnosiologia" e "a filosofia primeira se torna filosofia da consciência" (Agamben, 2014, p. 153). ${ }^{2}$

Como nota Agamben, filósofos "não profissionais", como Nietzsche, Benjamin e Foucault, e um representante da linguística histórica como Benveniste, é que foram capazes de escapar do transcendental kantiano. A busca pelo acesso ao a priori histórico deixa o âmbito da consciência, e passa a investigar a linguagem, e o sujeito transcendental de Kant também dá lugar ao falante, ao locutor. A língua passa a ser entendida, então, como o espaço privilegiado do ser, como o a priori histórico (Agamben, 2014, p. 154).

Para Agamben, porém, tal compreensão - que seria uma "declinação linguística da ontologia" - teria nos dias de hoje chegado ao seu total esgotamento, pois a linguagem assume um domínio onipresente, sobrepondose ao ser (Agamben, 2014, p. 154). Com isso, a linguagem funciona como uma massa amorfa, capaz de (aparentemente) abarcar todo o ser, não permitindo a permanência de algo como um resto, um não dito. ${ }^{3}$ Portanto, tal leitura não oferece uma explicação suficiente sobre a complexidade do ser. Nas palavras do filósofo italiano:

O que mudou é que a linguagem não funciona mais como um a priori histórico, que, permanecendo impensado, determina e condiciona as possibilidades históricas dos homens falantes. Identificando-se integralmente com o ser, ele se põe agora como uma efetualidade neutra a-histórica ou pós-histórica, que não condiciona mais algum senso reconhecível do devir histórico nem qualquer articulação epocal do tempo.

2 Todas as citações diretas desta obra são traduções nossas da original italiana.

3 Agamben afirma que isso é visivel na política, na comunicação e nas ciências da natureza. Podemos acrescentar a esses exemplos o direito, pois este, permeado pela ideologia liberal e pelo discurso neoliberal, é formado por enunciados que pretendem tudo dizer. 
Isso significa que vivemos em um tempo que não é - ou pelo menos pretende não ser - determinado por nenhum a priori histórico, isto é, um tempo pós-histórico (ou melhor, um tempo determinado pela ausência ou pela impossibilidade de tal a priori) (Agamben, 2014, p. 154).

Nesse sentido, Agamben propõe uma arqueologia da ontologia, ou melhor, uma genealogia do dispositivo ontológico que durante dois milênios funcionou como a priori histórico do Ocidente. E ressalva que o trabalho por ele desenvolvido em "O uso dos corpos" trata-se apenas de um começo, de um esboço sumário. Ainda, ele antevê ser a ontologia uma espécie de odologia (hódos em grego significa "caminho, via"), isto é, um estudo sobre o "caminho", sobre o "devir", "a via que o ser abre historicamente, a cada vez, voltando-se para si mesmo". Essa é a hipótese de Agamben. Por isso ele quer investigar a existência hoje de uma hódos, com o intuito de responder se o caminho "interrompido ou perdido" da filosofia primeira deva ser retomado ou, em vez disso, abandonado definitivamente (Agamben, 2014, p. 154).

Longe de resgatar aquele a priori histórico presente desde a metafísica aristotélica (e transformado em transcendental pela filosofia kantiana), parecenos que tal proposta aproxima-se mais da visão que os antigos gregos, présocráticos, construíram do ser: um ser que não é substantivado, mas que exprime ao mesmo tempo agente e verbo, o-que-está-sendo (tò ón) (Matos, 2011, p. 58). Guardaremos essa intuição, no entanto, para ser retomada mais adiante.

Como recorte metodológico, este artigo busca aprofundar os estudos na obra de Giorgio Agamben - "O uso dos corpos" - tendo em vista uma melhor compreensão da dimensão ontológica envolvida na sua construção conceitual, necessária para se pensar a proposta de "potência destituinte". Nesse sentido, buscar-se-á analisar a arqueologia da ontologia desenvolvida pelo autor nesse livro, tendo em vista ser esse um tema importante para a Filosofia Radical, a qual pretende refletir profundamente sobre as categorias nas quais nosso pensamento, nossa linguagem e nossas práticas encontram-se inseridas. Por se tratar de pesquisa complexa, ainda em andamento, nos ateremos neste primeiro momento a analisar de modo mais amplo a proposta agambeniana, para posteriormente articulá-la às noções de potência destituinte e de forma-de-vida.

\section{O dispositivo ontológico}

Agamben aborda como grande problema a ser desvelado por uma arqueologia da ontologia o dispositivo ontológico aristotélico, um dispositivo que "divide e ao mesmo tempo articula o ser". Esse dispositivo envolve, segundo Heidegger, a própria definição da metafísica ocidental, que é baseada em uma cisão, em 
uma “diferença ontológica" (Heidegger, 2005, p. 35). Isso porque, a ontologia - em suas acepções metafísicas - foi pensada no Ocidente a partir de estruturas duais que acompanharam e se somaram a outras díades no percurso histórico desse pensamento (essência primeira/essência segunda, existência/essência, ato/potência, natureza comum/existência singular [supposito], ser/ente etc.).

Em Aristóteles, essa cisão encontraria seu lugar nas "Categorias", um tratado que define tanto os gêneros do ser, em sentido ontológico - o ser em seus vários significados - quanto os elementos basilares da lógica. Nesse sentido, é importante ter em mente que tais "Categorias" são conceitos irredutíveis, que explicam o ser em sua origem e em suas variações e, ainda, fornecem os dados lógicos fundamentais de toda experiência, especialmente do pensamento e da linguagem.

Ao afirmar que o ser se diz de muitos modos, distinguindo quatro grupos fundamentais de significados (o ser como categorias ou "o ser em si", o ser como ato e potência, o ser como acidente e o ser como verdadeiro), Aristóteles atribuiu às categorias tanto o sentido de gêneros da predicação quanto o de gêneros do ser. O ser como categorias e o ser como ato e potência seriam próprios do domínio da metafísica, enquanto o ser como verdadeiro seria parte da lógica. Por sua vez, as categorias seriam o grupo principal dos significados do ser, isto é, as divisões originárias do ser, as quais constituem seus próprios "gêneros" - substância ou essência; qualidade; quantidade; relação; ação ou agir; paixão ou sofrer; onde ou lugar; quando ou tempo; ter; jazer (Reale, 1997, pp. V-XXXVI). Com essa confluência entre as definições do "ser em si”, ser e linguagem são articulados em uma relação onto-lógica, uma relação ambígua entre lógico e ontológico, na qual é impossível se distinguir uma instância da outra (Agamben, 2014, p. 157).

O ser em sua multiplicidade não pode ser dito por um nome comum, mas cabe ao pensamento recompor sob a forma da unidade o que a linguagem pressupôs e dividiu (Agamben, 2014, p. 160). Assim, no pensamento aristotélico, cada um e todos os significados do ser compartilham uma unidade, qual seja, a essência (ou substância), única categoria que, segundo Aristóteles, tem subsistência autônoma. A substância seria a mais elevada das categorias, da qual dependeriam todas as demais, e seria a única das categorias capaz de se dividir (Aristotele, "Metafisica", VII, 1030-1035). E parece-nos que é a partir daí que Agamben inicia sua investigação arqueológica.

A ontologia estaria fundada sob a cisão do ser-ousía - em um ser existencial (a ousía primeira) e em um ser predicativo (a ousía segunda, os modos como o 
ser "se diz"). ${ }^{4}$ No livro VII da "Metafísica", Aristóteles inaugura a determinação subjetiva da ousía, ${ }^{5}$ definindo que "o ser é constitutivamente alguma coisa que 'se diz' e 'significa"' (Agamben, 2014, p. 161), ou seja, pressupõe que o ser que se diz é desde sempre já na linguagem.

Nesse sentido, há uma suposta divergência entre o que Aristóteles enuncia na "Metafísica" e nas "Categorias": na primeira obra ele entende que a "substância primeira" encontra-se na forma e na essência da coisa, enquanto na segunda obra ele afirma ser a "substância primeira" o composto de matéria e forma (sinolo), sendo a "forma" a "substância segunda". Nas "Categorias", que são um tratado de lógica, Aristóteles parece considerar o sujeito (hypokeimenon) e o sinolo como substância primeira (pressupondo o sujeito pensante/falante), ${ }^{6}$ enquanto na "Metafísica" parece entender a "forma" - independente do sujeito - como a substância por excelência.

Essa aparente contradição do pensamento aristotélico, que parece ao mesmo tempo "afirmar e negar o primado do sujeito", tomando este como o que "estásob-e-no fundamento" (sub-iectum), como aquele que gerou a "prestação

4 Como explica Nicola Abbagnano, o significado predicativo do ser é interpretado na história da filosofia ocidental segundo três doutrinas: a da inerência, a da identidade e a da relação. A primeira delas, a doutrina da inerência, foi aquela inaugurada pela lógica aristotélica, cujo fundamento é a teoria da substância. Para Aristóteles, o ser predicativo "expressa a inerência ao sujeito de sua essência necessária, de determinações categoriais [...] ou de determinações acidentais". Dizer, por exemplo, que "Sócrates é animal bípede", é um caso de "inerência predicativa privilegiada", pois esta é a definição do homem (inerência da essência necessária à substância: ser animal). Outras determinações como "Sócrates é filósofo", por exemplo, seriam casos de inerência secundária ou acidental. Esse conceito do ser predicativo traz consigo as seguintes características fundamentais: "sua redução a um tipo único de relação, qualificada como pertença ou inerência"; e o "privilégio concedido à forma necessária dessa relação, ou seja, à forma como ocorre essa relação entre substância e essência". Essas características serão mantidas pela longa tradição que compartilha da doutrina da inerência, como Leibniz e Hegel. Para o primeiro, todo predicado verdadeiro teria um fundamento na natureza mesma das coisas e, assim, o predicado estaria contido no sujeito ("o predicado está no sujeito", é inerente a ele). Já para Hegel, "o significado predicativo de ser é a identidade entre individual e universal, ou seja, aquela mesma relação entre substância e essência que para Aristóteles era o caso privilegiado de relação predicativa". O ser predicativo significa para Hegel a "referência de um conceito ao sistema total da realidade", isto é, "a substância ou realidade à qual o predicado inere é a totalidade do real, em vez de ser (como na doutrina de Aristóteles) uma única substância" (Abbagnano, 2007, pp. 879-880).

5 Conforme desenvolvido por Matos em "O grande sistema do mundo", ousía significa o modo total do ser, o local do ser, o lugar em que o ser habita. O vocábulo grego foi erroneamente traduzido para o latim como substantia, tendo em vista a concepção metafísica do ser, que o concebe como "uma espécie de 'entidade', quer dizer, um escoadouro, um caldeirão sempre-existente de ser" (Matos, 2011, p. 55).

6 Isso se verifica, por exemplo, nas seguintes passagens das "Categorias": "Substância na acepção mais fundamental, primeira e principal do termo, diz-se daquilo que nunca se predica de um sujeito, nem em um sujeito, por exemplo, este homem ou este cavalo. No entanto podemos falar de substâncias segundas, espécies em que se incluem as substâncias primeiras, e nas quais, se são géneros, ficam contidas as mesmas espécies. Por exemplo: o homem individual inclui-se na espécie nominada homem, e, por sua vez, incluímos essa espécie no género chamado animal. Designamos portanto de segundas estas últimas substâncias, isto é, o homem e o animal, ou seja, a espécie e o género. [...] De modo que todas as coisas, sejam elas quais forem, excepção feita às substâncias primeiras, ou são predicados das substâncias primeiras, ou então acham-se nelas na acepção de sujeitos. E não havendo estas substâncias primeiras, não haveria nenhuma das outras substâncias" (Aristóteles, 1985, pp. 48-50). 
fundamental" (Agamben, 2014, pp. 163-167), foi o que legou ao pensamento ocidental a cisão entre essência e existência, como se o ser se dividisse "em uma essência inexistente [a forma] e em um existente sem essência". Como compreende Agamben (2014, p. 164), pensar o ser a partir daquele que "jaz-aofundo" significa definir um "existente inessencial" e uma "essência inexistente"?

Da cisão entre ser existencial e ser predicativo, a distinção entre ser e dizer não corresponde à oposição entre linguagem e ser, mas se relaciona aos significados do verbo ser: o ser designando algo que existe (ser existencial) e o ser exprimindo apenas uma relação lógico-gramatical entre dois termos (ser predicativo). Isso teria repercutido tanto nas estruturas linguísticas que nos foram transmitidas quanto no pensamento acerca da ontologia no Ocidente. Nas palavras de Agamben (2014, pp. 158-159),

Exatamente a promiscuidade entre os dois significados é que está na base de muitas aporias e dificuldades na história da ontologia ocidental, que se constituiu, por assim dizer, como uma máquina dupla, voltada a distinguir e, ao mesmo tempo, a articular juntas em uma hierarquia ou em uma coincidência as duas noções.

O dispositivo ontológico, portanto, seria estruturado pela contínua cisão do ser em essência e existência, pela divisão do ser "em um sujeito pressuposto sobre o qual algo se diz", e em uma "predicação" que se diz a partir do ser. Com tal divisão, o problema ontológico se coloca em como conhecer a essência, a substância primeira “o ser Sócrates de Sócrates”, o essencial do existencial (Agamben, 2014, p. 167).

Nesse sentido, entende Agamben que encontrar "a identidade do ser, que a linguagem cindiu, implica necessariamente" em introduzir o tempo no ser. Pois a linguagem é exatamente o fenômeno que marca o evento antropogenético, que liga o ser à história e ao tempo. Como aduz o filósofo italiano: "no mesmo gesto com o qual cinde o ser, a linguagem produz o tempo" (Agamben, 2014, p. 168).

Baseando-se na filologia de certas expressões presentes na obra aristotélica (como to ti en einai e ti einai), Agamben atribui o uso do verbo "ser" no passado à dimensão temporal que não pode ser afastada do dispositivo ontológico. $\mathrm{O}$ funcionamento deste exige um passado, o que leva Agamben (2014, p. 169) a pensar que o modo da existência presente nesse dispositivo, que envolve linguagem e sujeito, é “essencialmente temporal”. O filósofo italiano explica que essa dimensão é uma temporalidade interna ao sujeito, a qual

7 Tal afirmação é feita a partir das interpretações de Agamben da obra de Rudolf Boehm, "Das Grundlegende und das Wesentliche: zu Aristoteles' Abhandlung über das Sein und das Seiende". 
[...] não pode se tratar de uma temporalidade cronológica (como se a persistência do sujeito pudesse ser medida em horas ou em dias), mas de algo como um tempo operativo, como o tempo que a mente emprega para realizar a articulação entre o sujeito pressuposto e a sua essência. [...] A divisão do ser operada pelo dispositivo serve para colocar em movimento o ser, para dar-lhe tempo. O dispositivo ontológico é [assim] um dispositivo temporalizante (Agamben, 2014, p. 169).

É importante ter em mente que Aristóteles se insere na tradição que pensa o ser existencial não apenas como existência em geral, mas também, e especialmente, como existência primária. Ainda, filia-se (assim como Parmênides, Spinoza e Hegel) à metafísica clássica, a qual entende o ser existencial primário como necessidade, e não como possibilidade - esta seria uma característica da obra platônica (Abbagnano, 2007, pp. 883-885). A necessidade do ser para Aristóteles se realiza na substância, a qual impossibilita que o ser não seja. ${ }^{8}$ Mas se o ser se divide em uma essência primeira, a substância, e em uma essência segunda, um "agora" (uma forma material) que o torna problemático, ${ }^{9}$ a compreensão do ser implica sempre o tempo (Agamben, 2014, p. 170).

O estudo da ontologia nos mostra que uma característica da acepção do ser primário como possibilidade, como ocorre em Platão, Kierkegaard e Sartre, é que o problema do ser deixa de ser tratado em sua dimensão metafísica. Para autores assim, passam a ser analisadas caso a caso as possibilidades, nos campos específicos em que elas são gestadas, em sua concretude. Nesse sentido, não seria possível desenvolver uma "metafísica da possibilidade" em substituição (e tendo como espelho) o modelo da metafísica clássica da necessidade, pois isso consistiria em retornar a este modelo (Abbagnano, 2007, pp. 883-888). E isso, como nota Agamben (2014, p. 170), foi exatamente o que ocorreu com Heidegger: "a reproposição heideggeriana do problema do ser é uma retomada da ontologia aristotélica" e, por isso, permanece nas mesmas aporias desta.

O ser cindido em essência e existência e inserido no tempo, como produto da linguagem, é o legado que o dispositivo aristotélico deixou à filosofia ocidental. Nesse dispositivo, o sujeito é sempre pressuposto, e por isso mesmo ele é paradoxalmente o fundamento e o inacessível na dicção do ser (Agamben,

8 Tal se verifica, por exemplo, nas seguintes passagens: "Se a verdade tem significado, necessariamente quem diz homem diz animal bípede porque isso significa homem. Mas se isso é necessário, não é possível que o homem não seja animal bípede: necessidade significa exatamente isso: é impossível que o ser não seja." (Aristotele, "Metafisica", IV, 4. 1006 b 30); "É um só o significado do ser: a sua substância. Indicar a substância de uma coisa é indicar o seu ser" (Aristotele, "Metafisica", IV, 4. 1007 a 26).

9 De modo sintético, o chamado "problema do ser" consiste na afirmação simultânea de múltiplos significados do ser e de um significado único e fundamental, nos quais eles devem ser integrados (a essência ou substância, segundo Aristóteles). Haveria um "significado primário único e simples que se presume no ser, mas que permanece mais ou menos oculto na multiplicidade de seus aspectos aparentes". Este seria capaz de "expressar melhor do que os outros a existencialidade do ser", além de "possibilitar a integração dos outros significados, servindo-Ihes de fundamento ou princípio" (Abbagnano, 2007, p. 882). 
2014, p. 171). Segundo Agamben (2014, pp. 171-172), o que está em questão no dispositivo ontológico, bem como em todas as suas variantes históricas,

[...] é a articulação entre linguagem e mundo que a antropogênese desvelou como "história" aos viventes da espécie homo sapiens. Cindindo o puro existente (o que é) da essência (o que é isto) e inserindo entre esses o tempo e o movimento, o dispositivo ontológico ritualiza e repete o evento antropogenético, abre e define a cada momento o horizonte tanto do agir quanto do saber, condicionando [...] como um a priori histórico aquilo que o homem pode fazer e aquilo que ele pode conhecer e dizer. [...] na antropogênese o evento da linguagem pré-supõe como não (ainda) linguístico e não (ainda) humano aquilo que o precede. O dispositivo deve, então, capturar na forma da subjetivação o vivente, pressupondo-o como aquele sobre o qual se diz, como aquele que a linguagem, surgindo, pressupõe e remete ao fundamento. Na ontologia aristotélica, o hypokeimenon, o puro "que é", nomeia esse pressuposto, a existência singular e impredicável que deve ser ao mesmo tempo excluída e capturada no dispositivo.

Trata-se de um problema que envolve a inserção metafísica da singularidade na universalidade, surgindo daí a dificuldade de unificar ambas as instâncias em um quadro lógico que sirva como explicação geral do ser.

Nesse sentido, esse dispositivo, como a priori histórico que é, deixa também uma tarefa histórico-política em suspenso: conciliar, ou melhor, identificar a existência com a essência através do tempo. Sobre essa identidade cindida e articulada torna-se possível a fundação de uma ordem política, de uma pólis (Agamben, 2014, pp. 175-176). Por isso a definição do ser do homem está em Aristóteles ligada não apenas à sua vocação biológica de animal bípede, estando também atrelada à sua natureza política, capaz de unificar essência e existência, o gênero do qual faz parte o humano com a qualidade da vida política.

Nesse sentido, Agamben (2014, p. 176) parodia a tese teleológica aristotélica de que "a natureza existe no caminho que leva a si mesma" afirmando que se pode perfeitamente dizer, com base no dispositivo ontológico, que "a história é o caminho da natureza até si mesma (e não como na concepção corrente, algo separado desta)". ${ }^{10}$ É a história que acaba por ditar o ser existente e, consequentemente, busca ancorá-lo em uma natureza que confira unidade à multiplicidade entre aqueles que na ontologia aparecem como pressupostos: os sujeitos e as formas materializadas de poder. A impossibilidade da experiência de si reflete, desse modo, a impossibilidade de fazer com que coincidam o próprio existir e o próprio ser. ${ }^{11}$

10 Agamben parece referir-se aqui à distinção tradicional entre natureza e cultura, afirmada como pressuposto de várias construções filosóficas modernas, como aquelas presentes no pensamento político de Hegel.

11 Esta é a conclusão apresentada por Agamben sobre a impossibilidade de identificação do eu com o tempo, como tentou, sem sucesso, Heidegger. Por ditar a experiência, o tempo consistiria na própria medida (ou limite) que impede a experiência de si. Nesse sentido, afirma: "toda tentativa de atrelar o eu ou o tempo implica, por 


\section{Hipóstase e a cisão essência/existência}

Em sua arqueologia da ontologia, Agamben verifica que o termo ousía foi substituído pelos estoicos pelo termo hypostasis, usado para designar a existência. O significado original do termo refere-se a "base", "fundamento", mas também a "sedimento", "resíduo". Nesse sentido, a existência seria vista como resultado de um processo pelo qual "o ser se reifica e se dá consistência" (Agamben, 2014, pp. 180-181). Para os estoicos havia uma dimensão incorpórea do ser cuja natureza seria um processo e não uma substância. A hipóstase consistiria, exatamente, na passagem do "ser em si" para a existência, ou seja, seria uma operação secundária por meio da qual o ser se realiza na existência.

Tal substituição terminológica teria sua repercussão máxima com o neoplatonismo e a escolástica. Trata-se de uma experiência que encontra um paralelo (invertido) no recente existencialismo do século XX: hipóstase foi o termo utilizado para designar o "resíduo" da essência que caracteriza a existência. Nesse sentido, assim como os existencialistas entenderam haver um primado da existência sobre a essência, neoplatônicos como Plotino e Porfírio, contrariamente, enxergaram a primazia da essência sobre a existência (Agamben, 2014, p. 179).

Agamben (2014, pp. 179-184) nota a mudança do a priori histórico da filosofia aristotélica nos pensadores neoplatônicos e medievais. Em Aristóteles a separação entre essência e existência era estruturada a partir do hypokeimenon - do existente singular, do sujeito - para atingir a ousía. Assim, a essência era o que resultava de uma pergunta voltada a conhecer a existência específica (como ao se indagar sobre a natureza do homem, partindo da definição específica de ser este um animal bípede e, daí, afirmar sua essência animal). Já para os neoplatônicos há uma interpretação inversa desse processo: a hipóstase (existência) é concebida como uma "prestação da essência", pois a essência transcenderia a existência. Plotino, por exemplo, identificou com a hipóstase tudo o que procedesse do Uno, como a inteligência e a alma.

O pensamento neoplatônico busca deslocar a essência, o Uno (que depois será identificado com Deus), para além do ser. Diante disso, a existência é tida como hipóstase no sentido original do termo: como o "resíduo e o sedimento material daquele processo transcendente". O fundamento da existência, nesse contexto, seria apenas "uma operação, uma emanação ou uma efetivação do ser" (Agamben, 2014, p. 181), e a coisa gerada estaria em uma categoria 
hierarquicamente inferior em relação à essência que a realizou. Como aduz Agamben (2014, p. 182),

A ontologia neoplatônica procura conjugar o dispositivo aristotélico de cisão e articulação do ser com o impulso genuinamente platônico voltado a um para além do ser. O resultado é que o ser se torna um campo de forças tesas entre um princípio além do ser e as suas realizações (ou emanações na existência, chamadas hipóstases). À horizontalidade da ontologia aristotélica se substitui uma concepção decididamente vertical (alto/baixo; transcendência/hipóstase).

A divisão do ser operada pelo dispositivo aristotélico - essência/existência - mantém-se com o neoplatonismo e sua afirmação da hipóstase, mas a relação entre essas duas realidades é alterada. A tensão principal apontada por Agamben entre essas duas concepções metafísicas do ser é que na ontologia aristotélica vêse claramente a presença do tempo como o articulador entre sujeito pressuposto, linguagem e ser, enquanto no neoplatonismo está presente a eternidade de uma essência que se coloca para além do ser, ao mesmo tempo em que o realiza. Com isso, o tempo que estava implícito no dispositivo aristotélico assume a forma de um movimento circular das hipóstases (Agamben, 2014, p. 184), tornando-se extremamente problemática a relação ontológica entre a essência e a existência singular. Como nota Agamben (2014, p. 189),

[...] essencial é que a ontologia se torne agora um campo de forças tesas entre a essência e a existência, na qual os dois conceitos, em si teoricamente inseparáveis, tendam, no entanto, a afastar-se e a reaproximar-se segundo um ritmo que corresponde à crescente opacidade da sua relação. O problema da individuação - isto é, o problema da existência singular - é o lugar no qual essas tensões atingem a sua máxima lacuna.

Diversamente do dispositivo aristotélico que partia do hypokeimenon para conhecer a essência, a ontologia hipostática tem como ponto de partida a essência (ou substância) para chegar à existência singular, fazendo o caminho inverso que vai do universal para o particular (Agamben, 2014, p. 188). Provavelmente desse paradigma advenha a célebre formulação de Hegel, filósofo que supostamente rompeu, na época moderna, com o idealismo platônico: o racional é real; o real é racional.

O desenvolvimento mais bem acabado da teoria das hipóstases ocorre, segundo a leitura de Agamben, com a teologia trinitária, a partir da qual os padres da Igreja tentam explicar o dogma complexo de um Deus trino que é Uno. Isto é, um só Deus em três hipóstases realizadas ${ }^{12}$ pelo Uno, o qual é desde 
sempre a Trindade. Há nessa formulação uma evidente circularidade que torna ontologicamente problemática a relação entre a unidade e as três "pessoas" de Deus, sendo perfeitamente inteligível porque os debates oriundos dessa tese atravessaram os séculos separando hereges e fiéis.

Em sua reflexão sobre o problema da Trindade, qual seja, como é possível conciliar a unidade da essência com a pluralidade das três pessoas divinas, Agostinho elabora uma tese que definirá por séculos a forma em que se pensa "a relação". Eis sua tese: "Toda essência que se diz em modo relativo é algo, excetuado o relativo' (Omnis essentia quae relative dicitur est etiam aliquid excepto relativo)". Trata-se da exclusão da singularidade (sempre relativa) da definição da essência. O exemplo trazido por Agostinho para demonstrar sua teoria é o da relação entre senhor e escravo: se um homem é definido como senhor é porque está em relação com um escravo; mas a essência desse homem não se esgota no fato de ser senhor, pressupondo antes de tudo sua essência como homem. Somente por ser homem ele pode relacionar-se, na qualidade de senhor, e dizer-se de modo relativo senhor. O "ser-homem é o pressuposto substancial do ser-senhor, assim como o ser-Deus, a Trindade em si [...] é o pressuposto essencial das pessoas divinas em sua singularidade" (Agamben, 2014, p. 189).

Tal lógica relacional guarda semelhança com aquela exposta por Agamben em Homo sacer I: "o relativo é ao mesmo tempo excluído e incluído no absoluto, no sentido que [...] ele foi 'capturado fora', isto é, incluído por meio de sua exclusão". De modo similar, "a relatividade e a singularidade das pessoas foram capturadas na essência-potência unitária de Deus, de modo tal que elas são concomitantemente excluídas e incluídas nesta" (Agamben, 2014, p. 190). Dessa constatação pode-se extrair consequências visíveis ainda hoje, por exemplo, a acepção do sujeito como um sujeito de direito, cuja existência é continuamente gerada pelo poder político-jurídico graças à sua exclusão dessa esfera.

É com Heidegger que a diferença entre essência e existência, expressa pela díade ser/ente, se transforma no problema central da filosofia. Afirmando, de modo contrário ao neoplatonismo e à ontologia cristã, o primado da existência sobre a essência e, logo, do ente sobre o ser, Heidegger buscou pensar o "ser do ente", relegando para segundo plano o ser. Entende-se que tal característica aproximou o pensamento de Heidegger da vertente da ontologia que entende o ser como possibilidade, não como necessidade, herança platônica assumida pelo existencialismo do século XX, como já mencionado. A leitura de Agamben 
(2014, p. 191), no entanto, é feita a partir do conceito-chave de hipóstase: na obra capital de Heidegger ("Ser e tempo"), a ontologia aristotélica "é declinada em direção a uma ontologia hipostática. O ente abandonado do ser é algo como uma hipóstase neoplatônica ou gnóstica que, incapaz da epistrophè em direção ao Uno que a produziu, ocupa agora sozinha a cena do mundo".

Em "Ser e tempo" os processos históricos singulares foram abordados por Heidegger como manifestação do existente, do ser-aí, mas o autor não conseguiu fornecer uma explicação que desse conta da unidade histórica desses processos. Por sua vez, em sua obra posterior, "Contribuições à filosofia", Heidegger tentou reconstruir uma possível unidade do ser e, ainda, pensar para além dela. Segundo Agamben (2014, p. 191), porém, tal tentativa não obteve sucesso, pois "a única via para resolver as aporias da ontologia hipostática teria sido a passagem a uma ontologia modal". E é exatamente esse o desafio que se propõe o filósofo italiano em "O uso dos corpos".

\section{Ontologia modal}

No período referente à tardo-escolástica, filósofos e teólogos como Tomás de Aquino, Duns Scotus, De Bosses e Suárez se dedicaram ao tema do princípio de individuação. ${ }^{13}$ Apesar de concordarem sobre o argumento de que "a existência individual" acrescenta algo à essência, eles discordavam quanto à diferença entre essência e existência, bem como quanto à forma com que tais instâncias mantinham-se em relação. O ponto que une tais autores, e que interessou a Agamben, é o raciocínio comum de que "se a existência singular não pode ser simplesmente reduzida à essência, ela não pode nem mesmo ser separada desta como uma coisa de outra, uma essência de outra essência". Compartilhando dessa premissa, os autores buscaram definir os conceitos de "modo" e "diferença modal" a fim de definir, então, o estatuto particular da existência singular (Agamben, 2014, pp. 198-199).

A primeira teoria dos modos resgatada por Agamben é aquela de Egidio di Viterbo. Para ele, a diferenciação aristotélica entre o "ser em si”" e o "ser em outro" não é uma diferença essencial, mas apenas modal. Ao tratar da relação entre natureza comum e existência singular (supposito), Egidio definiu que ambas são diversas assim como "homem" e "humanidade" o são, mas tal diferença reside apenas nos modos que elas assumem. A humanidade se diferencia do homem materialização individual. 
singular assim como "a potência do ato, como uma res ainda não modificada difere da mesma res uma vez modificada" (Agamben, 2014, p. 201).

Na dicção de Scotus, a distinção modal é aquela que não consiste em uma diferença real - que é nas coisas -, assim como não se trata apenas de uma diferença de razão - que existe na mente -, mas de algo que se aproxima de uma distinção "formal", uma diferença entre as variadas formas em que algo $e ́$. E isso nada mais significa que "o ser dito". ${ }^{14}$ De Bosses acrescenta que o modo é "uma afecção da coisa, 'que determina o seu estado último e a sua razão de existir, sem, todavia, agregar a ela uma nova essência, mas somente modificando-a"'. No dizer de Suárez, o modo seria uma adição inessencial (Agamben, 2014, pp. 203-205).

Assim como a potência e o ato, essência e existência foram separadas pelo dispositivo aristotélico, e daí surgiram os grandes problemas da ontologia, que sempre perpassam a relação entre essas esferas cindidas do ser. Segundo a definição de Agamben (2014, p. 201), o modo é tanto lógico quanto ontológico e, portanto, aplica-se ao ser predicativo e ao ser existencial, à linguagem e ao mundo. Entender o ser a partir de seus modos é admitir, diversamente de Aristóteles, os acidentes e a contingência como partes integrantes do ser.

O modelo de uma ontologia modal foi desenvolvido por Spinoza ${ }^{15}$ na tentativa de apresentar uma solução para o problema da relação entre substância e modos. Como explica Agamben, a relação substância/modos não tem qualquer semelhança com as teorias escolásticas sobre "a passagem da natureza comum à existência individual ou da potência ao ato". Spinoza teria escolhido o termo "modo" porque este não significava apenas uma diferença de razão (de ordem mental), mas também era o que exprimia a menor diferença em relação à substância.

A tese ontológica central de Spinoza é que "nada existe além das substâncias e dos modos". Para ele, os modos não correspondem aos acidentes, pois estes existem apenas no âmbito do pensamento, não na realidade. Os modos são "afecções da substância", ou ainda, "afecções dos atributos de Deus", que "são em outro" (Agamben, 2014, pp. 208-209). Haveria, portanto, uma relação simultânea de identidade e diferença entre as coisas singulares e finitas e a substância única, Deus.

14 Como afirmará Agamben (2014, p. 217) em uma passagem mais adiante: “Um tal ser-dito não é concebido como um ser na mente, dependente da relação cognoscitiva de um sujeito: ele é a qualidade ou o caráter que o ente recebe enquanto é dito, enquanto sempre já recebeu um nome e, como tal, sempre foi pre-suposto". 15 Cuja filosofia não menciona o problema do princípio de individuação, típica da tardo-escolástica. 
É interessante observar que o modelo spinoziano não põe fim à ambiguidade entre lógica e ontologia legada pelo dispositivo aristotélico. No entanto, como entende Agamben (2014, p. 210), tal ambiguidade é um dado do qual não se pode escapar na tentativa de se pensar uma ontologia modal, pois

O conceito de modo - enquanto busca pensar a coincidência ou a indiferença de essência e existência, potência e ato - traz consigo uma ambiguidade pela qual ele se apresenta na história da filosofia ocidental ora como conceito lógico (prefere-se falar, neste caso, de "modalidades" e de lógica modal), ora como conceito ontológico. A indecidibilidade entre lógica e ontologia é [...] consubstancial ao conceito de modo e deve ser reconduzida à indecidibilidade constitutiva da onto-logia aristotélica, enquanto esta pensa o ser na medida em que é dito. Isso significa que a ambiguidade do conceito de modo não pode ser simplesmente eliminada, mas sim deve ser pensada como tal.

Uma das grandes dificuldades de se pensar modalmente, como ressalta Agamben, encontra-se no fato de estarmos habituados "a pensar de forma substantivada, enquanto o modo tem uma natureza constitutivamente adverbial", indicando, exatamente, circunstância, tempo e modo. Nesse sentido, a pergunta sobre o ser não se daria da forma clássica "o que é o ser?", mas sim “como o ser é?" (Agamben, 2014, p. 214). ${ }^{16}$ Em suas palavras,

Na fórmula que exprime o conteúdo da ontologia - o ser como ser - o pensamento se restringiu sobre os significados do ser como existência e essência, esquecendo-se do termo médio que une e ao mesmo tempo separa esses dois polos. O lugar próprio do modo está nesse termo médio, nesse "como". "O ser, que aqui é em questão, não é nem o quod est nem o quid est, nem um "que é" nem um "que coisa", mas um como. Este "como" originário é a fonte das modificações ("como" deriva etimologicamente de quo-modo). Restituir o ser ao seu como significa restituí-lo à sua com-moditas, isto é, à sua justa medida, ao seu ritmo e à sua comodidade (Agamben, 2014, p. 223-224).

Pensar em uma ontologia modal significa pensar, nesse sentido, em uma ontologia medial, assumindo assim uma inspiração de nítido recorte benjaminiano. É, portanto, uma pesquisa dos meios, não do princípio ou do fim. O exemplo de processo medial trazido por Agamben em "O uso dos corpos" é o uso. O uso, em termos filosóficos, é o que surge de um contato, de uma abertura de sentido que não define diferença ou identidade entre essência e existência, ser e ente, potência e ato. Ele emerge quando se desativa essas díades, quando se consegue habitar a pura medialidade. Como diz Agamben (2014, p. 215),

16 Agamben parece aproximar-se aqui da intuição de Foucault (1995) ao questionar-se não sobre o que é o poder, mas como o poder se exerce. 
"em uma ontologia modal, o ser usa de si, isto é, constitui, exprime e ama a si mesmo na afecção que recebe de suas mesmas modificações".

Tal ontologia inspira-se na ideia spinoziana de causa imanente, a qual não concebe o conceito de causa da forma como tradicionalmente foi pensado, sempre atrelado a uma hierarquia entre causa e efeito, seja priorizando a causa (essência primeira/essência segunda, essência/existência, forma/matéria) seja o efeito (potência/ato). A relação de causa imanente, por sua vez, "implica que o elemento ativo não cause o segundo, mas, mais do que isso, se exprima nele" e assim afirma "a imanência do expresso naquele que expressa e do passivo no ativo" (Agamben, 2014, p. 216). Em tal ideia, vê-se claramente a relação entre ser e modos, na qual não há diferença nem identidade substancial entre essência e existência, resolvendo-se, dessa forma, o "problema do ser". Nas palavras de Agamben (2014, p. 214),

O problema se resolve [...] se ele é colocado em termos de uma ontologia modal (admitido que se possa falar ainda de uma ontologia). Entre ser e modos a relação não é nem de identidade nem de diferença, porque o modo é ao mesmo tempo idêntico e diverso - ou, mais ainda, implica a coincidência [...] dos dois termos. Nesse sentido, o problema do risco panteísta é mal colocado: o sintagma spinoziano Deus sive natura não significa 'Deus = natureza': o sive (tanto derivando do se condicional e concessivo quanto do sic anafórico) exprime a modalização, isto é, o neutralizar-se e o vir a menos tanto da identidade quanto da diferença. Divino não é o ser em si, mas o seu sive, o seu já sempre modificar-se e "naturalizar-se" - nascer - nos modos.

"Deus, ou seja, a natureza" não implica identidade ou diferença entre ambos, mas um habitar entre um e outro. Essa construção filosófica constitui uma negação, ao mesmo tempo, da dualidade e da necessidade da reductio ad unum, uma prestação que a filosofia de Spinoza nos deixa como inspiração para se pensar uma nova ontologia.

Em "O uso dos corpos" Agamben deixa claro que a ideia de causa imanente seria sim uma categoria a ser pensada por uma ontologia modal. Isso porque se trata de uma ontologia que busca se subtrair dos problemas decorrentes das aporias do dispositivo aristotélico por meio de categorias capazes de fornecer uma correta compreensão da ligação entre ser e modos (Agamben, 2014, pp. 216218). Tal escopo inicia-se com a negação das fortes dicotomias que estruturaram o pensamento do ser desde Aristóteles, pois para uma ontologia modal

A essência não pode ser sem o relativo [o ser dito] nem o ser sem o ente, porque a relação modal - admitindo que se possa falar aqui de uma relação - passa entre o ente e a sua identidade consigo mesmo, entre a singularidade que tem o nome de Emma e o seu ser dito Emma. A ontologia modal tem lugar no fato primordial - que Aristóteles se limita a pressupor sem tematizá-lo - segundo o qual o ser sempre se diz: to on legetai... Emma não é a individuação particular de uma essência humana universal, 
mas, enquanto é um modo, ela é aquele ente pelo qual se encontra passando, no seu existir, no seu haver nome, no seu ser na linguagem (Agamben, 2014, pp. 217-218).

Agamben deixa-nos algumas pistas sobre essas novas categorias não aporéticas da ontologia modal, sem chegar, contudo, a sistematizá-las. O amor seria uma delas. Como na passagem em que Benjamin define o amor platônico como aquele que conserva e mantém em custódia o nome da amada e pelo qual a existência da amada provém do seu nome, assim como os raios proveem do sol, o amor seria capaz de compreender a relação entre uma coisa e o seu nome, relação esta que nada mais é que um ens debilissimum. Tal compreensão seria algo como a "consumação sem reservas da relação entre o ente e o seu ser na linguagem" (Agamben, 2014, p. 218).

Outra categoria a ser pensada, segundo Agamben, é aquela da exigência. $\mathrm{Na}$ sua longa arqueologia do pensamento ontológico, o filósofo italiano encontra no conceito de exigência, presente na obra de Leibniz, uma transformação da ontologia que ele busca desenvolver em nova perspectiva. A tese sobre a qual o trabalho de Agamben (2014, p. 208) irá se desdobrar é que "a existência não é um modo da essência, nem uma diferença apenas da razão: ela é uma exigência". Leibniz definiu a exigência como um atributo da possibilidade: o que é possível exige tornar-se real, assim como ocorre com a potência em relação ao ato e à essência em relação à existência. Nesse sentido, a existência seria para Leibniz uma exigência contida na essência, pois toda possibilidade conteria uma exigência (Agamben, 2014, pp. 218-219).

Embora a categoria de Leibniz da exigência mantenha a dicotomia entre essência e existência, potência e ato, desconsiderando a potência-de-não, Agamben busca pensá-la como um dado mais original do que as próprias definições dessas díades. Pensar o ser a partir de uma exigência significa pensá-lo como algo que é sem que necessariamente seja. Isso porque a exigência "não é da ordem da essência (não é uma implicação lógica contida na essência), mas tampouco coincide com a realidade atual". Ainda, escreve Agamben (2014, p. 220), "no onto-lógico" a exigência corresponde ao limiar "que une e ao mesmo tempo separa o ôntico e o lógico, a existência e a essência". A exigência corresponde à articulação entre os dois polos do dispositivo aristotélico (ser e ser dito), é o termo médio entre a linguagem e o mundo. Como coloca Agamben (2014, pp. 220-221), "se linguagem e mundo estão ligados sem nenhuma articulação, aquilo que aparece entre eles é uma pura exigência - isto é, uma dicidibilidade. ${ }^{17} \mathrm{O}$ ser é [em seu modo] uma pura exigência tensionada entre a linguagem e o mundo". 
A exigência seria um modo da potência. $\mathrm{O}$ real exige a possibilidade, e por isso não somente a possibilidade e a essência são transformadas pela exigência, mas também o ato e a existência, os quais perdem fixidez. Com a exigência de serem sempre possíveis, estes exigem a própria potência. Do ponto de vista da ontologia tradicional, "o ser mesmo, declinado à voz média, é uma exigência que neutraliza e torna inoperosas tanto a essência quanto a existência, tanto a potência quanto o ato" (Agamben, 2014, p. 221).

Com base na exigência, o ser não preexistiria aos modos, mas se constituiria modificando-se, sendo as suas próprias modificações. Tomando-se a exigência como categoria central da ontologia, o ser seria entendido como uma exigência dos modos, assim como os modos seriam uma exigência do ser. ${ }^{18} \mathrm{O}$ ser-queestá-sendo, de modo parecido como o conceberam os pré-socráticos (tò ón), é o ser que, nas palavras de Agamben (2014, p. 222), “deseja e exige, e exigindo, modifica, deseja e constitui a si mesmo".

O "modo" coincide com a existência singular, mas não se confunde com um mero fato nem com a substância, pois, como dito, ele não se define estritamente em uma potência ou em uma atualidade. O modo é "uma série infinita de oscilações modais por meio das quais a substância se constitui e se exprime", como redemoinhos que no campo difuso da substância exprimem e disseminam as singularidades. O modo é "um vórtice no fluxo do ser" (Agamben, 2014, pp. 223-226).

Ao final de sua arqueologia da ontologia, Agamben a "conclui" deixandonos, na verdade, uma tarefa, a qual abre um novo campo de investigações para a Filosofia Radical. Se o ser é sempre o seu modo de ser - isto é, o ser é radicalmente modo -, o modo em que algo é corresponde, da mesma maneira que o ethos, ao "ser assim" do ente. Então, pensar corretamente o modo significa compreendê-lo em um limiar de indiferença entre a ontologia e a ética. Uma ontologia modal, portanto, não seria somente uma ontologia em seu sentido clássico, mas também uma ética, uma ética dos modos.

\section{Considerações finais}

A ontologia modal esboçada por Agamben parece aproximar-se mais de uma interpretação do ser como possibilidade do que como necessidade. Porém, o filósofo faz uma leitura completamente diversa dessa concepção, tradicionalmente 
ligada ao pensamento platônico, e, ainda, não deixa de se valer das teorias que veem o ser como necessidade para construir sua própria proposta.

Longe de se aproximar de correntes determinadas, como o existencialismo e o heideggerianismo, Agamben tenta demonstrar por meio de sua arqueologia as aporias que lhes são inerentes, tomando como enfoque principal nesse estudo a dicotomia essência/existência. Sua proposta é pensar o ser sem qualquer determinação dicotômica que o separe e o hierarquize em duas realidades contrapostas e dependentes.

A filosofia ocidental é, sem dúvida, construída com base em aporias $a$ priori e postulados rígidos. Esse fato, além de trazer implicações em vários ramos do saber, determina sobremaneira os modos com que estruturamos nosso pensamento, nossas linguagens, nossas práticas e criamos nossas instituições sociais.

O que Agamben inicia com seu projeto é uma tentativa de profanação da própria filosofia ocidental: trata-se de uma demonstração de que o postulado segundo o qual é impossível se desenvolver uma metafísica da possibilidade só se sustenta se assumimos a metafísica de um Aristóteles, por exemplo, como dogma. E isso é o avesso do pensar filosófico.

Agamben oferece demonstrações suficientes de que é possível sim pensar o ser, em todas as suas complexidades, sem restringi-lo às categorias. Reconstruindo o conceito de modo, ele mostra que na relação entre ser/modos o que está em jogo não é o conhecimento de uma origem primeira ou de uma teleologia: o que importa é compreender o como, os modos não fixos do ser em seu contínuo movimento.

Se isso será uma ontologia ou uma ética - ou ainda, uma odologia - não é possível neste momento afirmar. É preciso conectar os preciosos desenvolvimentos sobre a ontologia modal, que este artigo buscou compreender, com as noções de forma-de-vida e de potência destituinte.

\section{Referências}

ABBAGNANO, N. Ser. In: . "Dicionário de filosofia". $5^{\mathrm{a}}$ ed. Tradução de Alfredo Bosi e Ivone Castilho Benedetti. São Paulo: Martins Fontes, 2007. pp. 878-888. AGAMBEN, G. “L'uso dei corpi”. 2a ed. Vicenza: Neri Pozza, 2014. ARISTOTELE. "Metafisica". Tradução de Giovanni Reale. $3^{\mathrm{a}}$ ed. Milano: Rusconi, 1997. ARISTÓTELES. Categorias. In: . "Organon". Tradução de Pinharanda Gomes. Lisboa: Guimarães Editores, 1985. pp. 41-118.

. "Política" [Capítulo I, Livros I e II]. Tradução de José Oscar de Almeida Marques. Departamento de Filosofia, IFCH-Unicamp [Online]. Disponível em: www.unicamp. br/ jmarques/cursos/1998-hg-022/politica.doc. (Acessado em 28 de junho de 2017). 
FOUCAULT, M. Sujeito e poder. In: DREYFUS, H. \& RABINOW, P. "Michel Foucault, uma trajetória filosófica: para além do estruturalismo e da hermenêutica". Tradução de Vera Porto Carrero. Rio de Janeiro: Forense Universitária, 1995. pp. 231-249.

HIDEGGER, M. "Ser e tempo". Parte I. 15ª ed. Tradução de Marcia Sá Cavalcante Schuback. Petrópolis: Vozes, 2005.

HOUAISS, A. "Dicionário eletrônico Houaiss da língua portuguesa". Rio de Janeiro: Objetiva. Versão 3.0 [CD-ROM], 2009.

MATOS, A. S. M. C. "O grande sistema do mundo: do pensamento grego originário à mecânica quântica”. Belo Horizonte: Crisálida, 2011.

REALE, G. Introduzione. In: ARISTOTELE. "Metafisica". $3^{\text {a }}$ ed. Tradução de Giovanni Reale. Milano: Rusconi, 1997. pp. XXI-XXV. 